\title{
Qualitative and Quantitative Study on Components of Future Time Perspective and Their Association with Persistent Treatment for Type 2 Diabetes
}

\author{
Tomoo Hidaka (D) - Noriko Takahashi - Katsue Hashimoto • \\ Mariko Inoue · Yukiko Terada - Shota Endo · Takeyasu Kakamu • \\ Taro Tsukahara $\cdot$ Koichi Abe $\cdot$ Tetsuhito Fukushima
}

Received: August 29, 2021 / Accepted: October 14, 2021 / Published online: October 27, 2021

(C) The Author(s) 2021

\begin{abstract}
Introduction: Future time perspective (FTP) means the capacity to foresee, anticipate, and plan for future desired outcomes, and it contributes to persistent treatment for type 2 diabetes mellitus (T2DM). However, the components of FTP specific to T2DM patients have not been clarified. This study aimed to explore the components of FTP and to examine the associations between such components and persistent/impersistent diabetes treatment.

Methods: In this cross-sectional study, using qualitative and quantitative methods, 106 T2DM patients were enrolled by purposive sampling. The participants were interviewed in October and November 2018 by public health
\end{abstract}

T. Hidaka $(\varangle) \cdot$ S. Endo · T. Kakamu · T. Fukushima Department of Hygiene and Preventive Medicine, Fukushima Medical University, Hikarigaoka 1, Fukushima, Fukushima 9601295, Japan

e-mail: thidaka@fmu.ac.jp

N. Takahashi $\cdot$ K. Hashimoto $\cdot$ T. Tsukahara Koriyama City Public Health Center, 15-1, Asahi 2, Koriyama, Fukushima 9638024, Japan

M. Inoue $\cdot$ Y. Terada

CMR Development Division, Novo Nordisk Pharma Ltd., 2-1-1, Marunouchi, Chiyoda-ku, Tokyo 1000005, Japan

K. Abe

Igarashi Clinic of Medicine and Surgery, 12-7,

Namiki 2, Koriyama, Fukushima 9638026, Japan nurses in Koriyama City Public Health Center, Japan. In addition to the participants' status of treatment engagement (persistent/impersistent), their responses regarding reasons for persistent/impersistent treatment were collected and then summarized into nine subthemes, which were then merged into two main themes according to the presence or absence of FTP with a sense of T2DM ownership for analysis.

Results: The main theme, "presence of FTP with a sense of T2DM ownership," included subthemes such as "securing social independence," "planning on living a long and healthy life," "prioritizing avoiding being a burden on family and friends," "valuing improvement of diabetes," "avoiding tragic results," "optimistically viewing treatment as a form of self-development," and "improving mental health," whereas the main theme, "absence of FTP with a sense of T2DM ownership," included "lack of consciousness of disease" and "living a dissipated life." The association between the presence of FTP with a sense of T2DM ownership and persistent treatment for T2DM was found using Fisher's exact test $(p<0.001)$.

Conclusion: Health care professionals should support T2DM patients in having an FTP with a sense of T2DM ownership and purpose in life instead of treatment goals when such patients mention their dissipated life or lack of insight into the disease. 
Keywords: Behavioral medicine; Future time perspective; Hybrid thematic analysis; Meaning; Qualitative study; Type 2 diabetes

\section{Key Summary Points}

Why carry out this study?

This study was based on the hypothesis that patients with type 2 diabetes who do not have a stable future time perspective are likely to stop their diabetes treatment

By asking patients with type 2 diabetes why they do or do not engage in persistent treatment, this study explored the components of future time perspective, i.e., what constitutes such a perspective for an individual

\section{What was learned from the study?}

The qualitative and quantitative analysis showed that patients with no future time perspective and no a sense of type 2 diabetes ownership, such as those who lacked consciousness of the disease despite a definite diagnosis or those who had a dissipated life, had difficulty engaging in persistent treatment

For patients with type 2 diabetes who lack a future time perspective with a sense of type 2 diabetes ownership, provision of purpose in life instead of treatment goals may contribute to improved persistent treatment engagement

\section{INTRODUCTION}

Future time perspective (FTP) means the capacity to foresee, anticipate, and plan for future desired outcomes [1], and it contributes to persistent treatment for type 2 diabetes mellitus (T2DM) as a result of its association with the improvement of medication adherence [2] and dietary habits [3]. In contrast, the absence of such a perspective is associated with reduced motivation regarding goal achievement [4] and is therefore considered to be associated with treatment impersistence.

However, the characteristics of FTP specific to T2DM patients have yet to be clarified. The scales used in past studies [2-4] for measuring the time perspective of T2DM patients, such as the Time Perspective Questionnaire [5] or Zimbardo's Time Perspective Inventory [1], were composed of abstract items applicable to everyone. Although such abstract items maintain the scales' generalizability to a wide range of people, including T2DM patients, these past scales cannot be used to fully analyze FTP among T2DM patients. Identification of the components of FTP in T2DM patients is beneficial for health care professionals, so that they can help toughen the resolve of these patients, if necessary, and such identification would provide fundamental knowledge of factors associated with treatment persistence/impersistence; therefore, we believe that there is room for exploratory research in this area.

The purpose of this study was to explore the components of FTP among T2DM patients who persistently/impersistently engage in the treatment and to examine the associations between themes as a brief representation of components of FTP and persistence/impersistence of treatment for T2DM, using both qualitative and quantitative methods.

\section{METHODS}

\section{Setting and Sampling}

In this cross-sectional study, purposive sampling was employed to select 110 potential participants aged $\geq 40$ years, who lived in Koriyama City, Fukushima Prefecture, where the total population was 329,903 and the number of people aged $\geq 65$ accounts for $28.2 \%$ of its total population, which is similar to that of Japan (28.9\%). All potential participants had a medical history of T2DM recorded in the Fukushima National Health Insurance Organization database. First, treatment engagement status was defined as "impersistent" when a participant's treatment medical record was 
absent for a continual period of $\geq 6$ months on the said database and "persistent" when there was a record of the participant receiving treatment at least once every 6 months. As much as possible, the study population was organized to reflect the proportions of patients with persistent/impersistent engagement in treatment in Koriyama City as a whole. Of the 110 potential participants, 4 were excluded from analysis because their self-reported treatment engagement status was critically different from their medical records, such as individuals who reported during the study that they did not remember whether they had been diagnosed as having T2DM. Finally, 106 participants were enrolled in the present study.

\section{Procedure and Measurement}

One-to-one interviews with participants were conducted by public health nurses in Koriyama City Public Health Center in October and November 2018. Prior to the interviews, to refine the procedure and questions, the nurses were trained how to conduct a research interview by the first author, who specializes in qualitative study in psychology. Additionally, an interview guide was created by the first author under the supervision of the sixth and seventh authors, who are both medical doctors. In interviews, each participant's treatment engagement status was specifically confirmed, and FTPs regarding treatment engagement were interviewed semi-structurally using the following questions, depending on the context of the conversation: "What is more important than your health/diabetes treatment?," "What do you think the treatment is for?," and "Do you have any plans regarding what you want to do after completing treatment or after your health has improved?" Each participant was interviewed once, and the mean interview length was $29.4 \mathrm{~min}$. Each interview was digitally recorded with the permission of the respective participant, was transcribed verbatim by a professional transcriptionist, and was then analyzed by the authors.

\section{Qualitative and Quantitative Analysis}

To identify the components of FTP, we inductively coded the interview transcripts via a hybrid thematic analysis [6], assigning a label to each fragment of the transcript that had a similar underlying meaning and thus could be merged into a larger concept, based on the following procedures presented in past literature [7]: familiarizing with the data, generating initial codes, searching for themes, reviewing themes, defining and naming themes, and producing an overall analysis. For further statistical analysis, the definition of each theme was carefully determined to differentiate each theme from other themes. One hundred eightyone fragments of the transcripts were subjected to analysis, and these fragments were summarized into 26,9 , and then finally 2 categories in the coding steps. The final two categories were treated as "main theme," whereas "subtheme" for the semi-final nine categories. Although both main and subthemes reflected the components of participants' FTP, the main theme was created by dichotomizing nine categories of subtheme in terms of whether participants had a sense of ownership of T2DM or not, whereas subtheme had more concrete explanations regarding individual's subjective meaning on treatment engagement than the main theme. Subjects' narratives showed that the presence of a sense of ownership of T2DM, such as the perception that T2DM could be self-inflicted, was associated with both FTP and treatment persistence/impersistence. Thus, the phrase "sense of ownership of T2DM" was considered to be a suitable name for the main theme. The main theme, which consists of two categories, was considered suitable for quantitative analysis because of a sufficient sample size per category, whereas the subtheme was employed in qualitative analysis to describe comprehensively the actual status of thoughts of participants.

For quantitative analysis, using the main theme as a brief representation of components of FTP, the association between the components of FTP and treatment engagement status was examined by chi-square test with Fisher's exact test. The significance level was set at 5\%. 
The MAXQDA Analytics Pro 2018 software (VERBI GmbH, Berlin, Germany) was applied for qualitative analysis, which was performed during May to December 2020, whereas SPSS statistics version 26 (IBM, NY, USA) was used for quantitative analysis, which was performed in February 2021.

\section{Ethics}

This study was approved by the Ethics Committees of Fukushima Medical University (application no. 30196). Our study was performed in accordance with the Helsinki Declaration of 1964 and its later amendments, and all participants provided written informed consent to participate in the study.

\section{RESULTS}

Regarding the characteristics of participants $(N=106), 60(56.6 \%)$ were males, and the mean age was 68.4 (SD 4.2) years. For treatment engagement status, the numbers of persistent and impersistent engagement were 89 (83.9\%) and $17(16.1 \%)$, respectively.

The main and subthemes, as the components of FTP, with related information are shown in Table 1 . Note that the number of fragments (181) that constituted the main and subthemes was inconsistent with the number of participants (106); this is because some participants provided responses that could be matched with multiple themes.

The subtheme "securing social independence" was comprised of responses that emphasized autonomy/independence in social life, such as earning money, having a role in the community and family, or maintaining high activity of daily living. This theme included the following fragments of participants' thoughts: 'I have worked as a volunteer case worker in my community. This kind of contribution to the community, trying various things at my own pace, including the volunteer work, is important in terms of having a purpose for living' (70s, male). 'Health is wealth, our body is an asset. I do not want to be confined to my bed because I will not be able to earn any money' (60s, male). 'I want to choose what I eat and drink. I am not receiving any special treatment for diabetes. I just want to make my own decisions about myself., I want to remain healthy enough to live an independent life' (60s, female).

The subtheme "planning on living a long and healthy life" reflected a strong conviction that the treatment of diabetes will lead to a long, healthy, and happy life. This theme included responses such as: 'No doubt there is nothing more important than health. You cannot do anything when you are in frail health, even if you win a tremendous amount of money in the lottery' (70s, male). 'I think that good health equals a long life. This is the primary reason for treatment, as far as I'm concerned' (60s male). 'Honestly, I do not think about my life with diabetes seriously. For me, I may come across something enjoyable if I have a long life' (60s, male).

The point of the subtheme "prioritizing avoiding being a burden on family and friends" was a fear of becoming a burden on family, kin, or friends as a result of not keeping up with treatment; this theme consisted of responses from participants who did not want to become a cause of trouble for their loved others in the future: 'I do not want my family, including my daughter and her husband, to have to sacrifice their time to take care of me. They have jobs, and they should focus on themselves instead of me. So, I think the maintenance of my health is most important for me' (60s, female). 'I belong to my family so that if my health were to decline, it would cause more work for my family. My body is not only for me but also for my family' (70s, male). 'I would rather die soon than live a long life, if I become a cause of trouble for my family, or society. Of course, I would welcome a long life if it were a healthy one' (60s, female).

The subtheme "valuing improvement of diabetes" consisted of responses indicating that treatment engagement may have a positive impact on the participants' lives in the future, even if the responses were speculative: 'Persistent treatment engagement, such as hospital visits, taking medicine, and maintaining a healthy diet, is a part of my life. I am used to 
Table 1 Themes emerging as a result of inductive coding and their explanations

\begin{tabular}{|c|c|c|}
\hline Main theme & Subtheme & $\begin{array}{l}\text { Definition/explanation for } \\
\text { corresponding subtheme }\end{array}$ \\
\hline \multirow[t]{2}{*}{$\begin{array}{l}\text { Presence of FTP with a sense } \\
\text { of T2DM ownership }\end{array}$} & Securing social independence $(50)$ & $\begin{array}{l}\text { Emphasis on autonomy/ } \\
\text { independence in social life, such } \\
\text { as earning money, having a role } \\
\text { in the community and family, or } \\
\text { maintaining high activity of } \\
\text { daily living. Unlike another } \\
\text { subtheme, "prioritizing avoiding } \\
\text { being a burden on family and } \\
\text { friends," which is characterized } \\
\text { by a concern that the individual } \\
\text { may become a burden to their } \\
\text { family and friends, the focus is } \\
\text { on the desire to maintain their } \\
\text { own place in society by retaining } \\
\text { their physical abilities in future }\end{array}$ \\
\hline & Planning on living a long and healthy life (42) & $\begin{array}{l}\text { Conviction that the treatment of } \\
\text { diabetes will lead to a long, } \\
\text { healthy, and happy life. } \\
\text { Although this theme does not } \\
\text { necessarily include an explicit } \\
\text { aim or purpose of treatment for } \\
\text { the future, the responses in this } \\
\text { theme clearly indicate the } \\
\text { presence of a perspective } \\
\text { suggesting that the participants } \\
\text { consider the relationship } \\
\text { between diabetes and their } \\
\text { future life as their own affairs. } \\
\text { As with this theme, the } \\
\text { responses in the theme "valuing } \\
\text { improvement of diabetes" do not } \\
\text { explicitly disclose the aim or } \\
\text { purpose in the future. However, } \\
\text { the theme "planning on living a } \\
\text { long and healthy life" puts the } \\
\text { focus on health in the relatively } \\
\text { distant future, while the focus of } \\
\text { theme "valuing improvement of } \\
\text { diabetes" is on health in the near } \\
\text { future such as daily medication } \\
\text { and regular hospital visits }\end{array}$ \\
\hline
\end{tabular}


Table 1 Themes emerging as a result of inductive coding and their explanations

\begin{tabular}{|c|c|c|}
\hline Main theme & Subtheme & Definition/explanation for corresponding subtheme \\
\hline & $\begin{array}{l}\text { Prioritizing avoiding being a burden on family and } \\
\text { friends (35) }\end{array}$ & $\begin{array}{l}\text { Fear of becoming a burden on family, kin, or friends for } \\
\text { their nursing care as a result of impersistent treatment } \\
\text { and concerns about negative consequences for } \\
\text { interpersonal relationships due to treatment withdrawal. } \\
\text { This theme is unique for its focus on interpersonal } \\
\text { relationships in the future. Both this theme and } \\
\text { "avoiding tragic results" place the emphasis on the effort } \\
\text { to decrease the chances of a negative future }\end{array}$ \\
\hline & Valuing improvement of diabetes (30) & $\begin{array}{l}\text { Focuses on persistent treatment contributing to a better } \\
\text { future. Although the responses included in this theme } \\
\text { are somewhat speculative, they represent a certainty that } \\
\text { persistent treatment leads to positive results. This theme } \\
\text { should be distinguished from the theme "planning on } \\
\text { living a long and healthy life" by its focus on the near } \\
\text { future }\end{array}$ \\
\hline & Avoiding tragic results $(8)$ & $\begin{array}{l}\text { Intention to avoid severe physical outcomes of diabetes in } \\
\text { the future, such as leg amputation and diabetic cataract. } \\
\text { This theme is characterized by avoidance rather than } \\
\text { escape, referring to the acquaintances' actual experiences } \\
\text { regarding such severe outcomes or advice from medical } \\
\text { professionals. This theme is distinguished from the } \\
\text { theme "prioritizing avoiding being a burden on family } \\
\text { and friends" by its focus on the risks of type } 2 \text { diabetes } \\
\text { for physical health, while both themes have a pessimistic } \\
\text { future perspective in common }\end{array}$ \\
\hline & $\begin{array}{l}\text { Optimistically viewing treatment as a form of self- } \\
\text { development (5) }\end{array}$ & $\begin{array}{l}\text { Very positive perspective in which individuals have many } \\
\text { growth opportunities for themselves to know the life } \\
\text { with diabetes and its treatment; in other words, they } \\
\text { consider the experience of the disease and treatment to } \\
\text { gain new knowledge about their body, mind, lifestyle, } \\
\text { and society }\end{array}$ \\
\hline & Improving mental health (3) & $\begin{array}{l}\text { Appreciation of treatment engagement as a reasonable } \\
\text { option for achieving better mental health; life with } \\
\text { diabetes makes individuals anxious, and the anxiety will } \\
\text { be reduced by undergoing treatment. In other words, } \\
\text { engagement in treatment is a means of improving mental } \\
\text { health }\end{array}$ \\
\hline \multirow[t]{2}{*}{$\begin{array}{l}\text { Absence of FTP with a sense of } \\
\text { T2DM ownership }\end{array}$} & Lack of consciousness of disease (5) & $\begin{array}{l}\text { Attitude of individuals who do not have a clear future time } \\
\text { perspective, characterized by inactive and passive } \\
\text { engagement in treatment and recognition of diabetes as a } \\
\text { disease that is totally unrelated to their life and health }\end{array}$ \\
\hline & Living a dissipated life (3) & $\begin{array}{l}\text { Situation in which he/she cannot quit unhealthy lifestyle } \\
\text { habits, such as binge drinking and eating, despite being } \\
\text { fully aware of the outcomes of such habits. Although } \\
\text { they may have an FTP, they may be caught up in } \\
\text { unproductive thoughts and/or lifestyles }\end{array}$ \\
\hline
\end{tabular}

The number of fragments included in each subtheme is indicated in the brackets. The number of fragments was inconsistent with the number of participants since their answers could be matched with multiple themes 
living a normal life while undergoing treatment for diabetes' (70s, female). 'It is a matter of course that I, a person with T2DM, go to a doctor and take my medication properly. I do what I am expected to do, and have engaged in treatment. That is the only way to manage diabetes' (60s, male). 'Six years have passed since I was diagnosed as having T2DM. For all this time, I have regularly undergone treatment, and I will continue to do so' (70s, male).

For the "avoiding tragic results" subtheme, the outcomes of T2DM treatment and their impact on physical health were mentioned as the reasons for engagement in treatment, emphasizing very pessimistic views of the future if treatment were stopped. The characteristics of this theme were exemplified by the following responses: 'I fear both insulin injection and leg amputation. The primary reason for treatment engagement is to avoid them' (60s, male). 'Now I am really careful not to aggravate my diabetes as much as I can. I also need to control hypertension in addition to diabetes, because my father had both diabetes and hypertension, which led to him having a fatal cerebrovascular event. With these events and experiences, I try to maintain my treatment' (50s, male).

Regarding the subtheme "optimistically viewing treatment as a form of self-development," the participants accepted T2DM and its treatment focusing on the positive aspects of having diabetes. They stated that after having T2DM, they learned about the social systems and body structure and understood the feelings of other patients. The responses included: 'Struggling with diabetes, I realized that my health declines as I age. Health is important; however, nobody can remain healthy forever. Although I thought that the key to health and happiness was to avoid getting sick or to cure it when I was young, there may be health management methods suitable for elderly people. I could realize them after treatment engagement. Whether at work or elsewhere, I believe that life gives me lessons and I am glad to have such opportunities' (60s, male). 'The treatment of diabetes is my highest priority. When I am healthy, I can go anywhere and study many things in my life' (60s, female).

The subtheme "improving mental health" consisted of responses of appreciation of the mental health benefits gained by engaging in the treatment rather than the physical health benefits resulting from the treatment. This is characterized by the following: 'It is important not to get depressed. The worse the diabetes, the worse the problems it brings. If that happens, I will surely lose vitality. Therefore, I had better continue with my treatment' (60s, male). 'It is a matter of way of thinking. I try to look on the bright side of everything, including diabetes and its treatment; it makes my life happier' (70s, female).

The subtheme "lack of consciousness of disease" was characterized by participants' inactive, passive, or uncooperative attitudes toward T2DM treatment. This theme comprised responses that emphasized the absence of reasons to continue treatment: 'I have no idea what is important for my life in relation to health, treatment, or lifestyle. Actually, I do not think I have diabetes now. I am healthy' (70s, male). 'In my mind, diabetes is not connected to my health. People often say that they want to

Table 2 Associations between treatment engagement status and presence/absence of FTP with a sense of T2DM ownership

\begin{tabular}{llcc}
\hline Variable & \multicolumn{2}{l}{ FTP with a sense of T2DM ownership } & \\
\cline { 2 - 4 } & Present & Absent & \multicolumn{1}{c}{-value } \\
\hline Treatment engagement status & & & \\
Persistent & $148(85.5)$ & $1(12.5)$ & \\
Impersistent & $25(14.5)$ & $7(87.5)$ & \\
\hline
\end{tabular}

$n$ (\%) for the number of fragments included in the category

${ }^{*}$ Examined by Fisher exact test 
live long, or health is first. But, I don't think so at all' (70s, male).

The subtheme "living a dissipated life" was characterized by self-destructive lifestyles and behavior. In this theme, responses indicated a lack of sense of ownership of T2DM: 'If you ask me what is more important than my health, it doesn't come to mind. I enjoy drinking alcohol. I do not have enough friends or hobbies, and I do not have much fun except for drinking. I know the consequences of this lifestyle, and I will accept them when they come' (60s, male).

For quantitative analysis, Fisher's exact test was conducted to examine the association between treatment engagement status and FTP with a sense of T2DM ownership. As shown in Table 2, statistically significant associations were observed $(p<0.001)$.

\section{DISCUSSION}

In the present study, we extracted nine subthemes and two main themes that are assumed to be the components of FTP in T2DM patients and also examined the association between presence/absence of FTP with a sense of T2DM ownership, which is a brief representation of components of FTP, and treatment engagement status. The seven subthemes corresponding to the main theme "presence of FTP with a sense of T2DM ownership" were associated with persistent treatment, while the two themes corresponding to the main theme "absence of FTP" were associated with impersistent treatment. These results can be used beneficially for promoting behavior modification and persistent treatment engagement among T2DM patients. For comprehensibility, in this section, the results of analyses are discussed in the reverse order from that in the "Results" section: statistical analysis results followed by qualitative analysis results.

The statistical analysis results indicate that the presence of FTP with a sense of T2DM ownership is associated with persistent treatment engagement. This suggests that the presence of such a perspective is essential for persistent treatment engagement. Although past studies have reported similar results
$[2,3,8]$, in the present study, we were able to qualitatively identify the components of FTP as shown in seven subthemes.

The subtheme "securing social independence" focused on independent/autonomic life in society. Therefore, the participants whose responses were included in this theme were considered to have correctly recognized T2DM as a potential threat to his/her future social independence. These results support a past study that indicated a strong association between the fulfillment of social role and a sense of independence among T2DM patients [9].

The responses in the theme "planning on living a long and healthy life" represented the presence of goals in the distant future instead of the near future; in other words, the participants whose responses were included in this theme may have had a long-term perspective. Having a long-term time perspective is associated with improved self-control since this perspective influences the incentive value of their motives [10]. Importantly, it has been reported that positive personal characteristics such as selfcontrol, self-efficacy, and self-esteem are associated with diabetes management and glycemic control in diabetic patients $[11,12]$. Given these past studies, the presence of a distant future goal, such as long and healthy life, may have contributed to the improvement of both the participants' sense of self-control and actual diabetes management, leading to persistent treatment.

The background of the theme "prioritizing avoiding being a burden on family and friends" may be comprehended from the viewpoint of cultural and social contexts, which exist particularly among Asian people, regarding becoming a care burden. Eastern Asian people, including Japanese people, the participants in this study, tend to culturally consider that burdening others is highly discourteous and should be avoided [13]. Such a tendency is a norm observed even in individuals in a life-threatening condition due to fatal diseases such as cancer $[14,15]$. Because the number of fragments belonging to this theme was larger than that in the theme "avoiding tragic results," concerns regarding trouble in interpersonal relationships 
may be a more common element of FTP than physical health concerns among the participants of the present study.

The responses in the theme "valuing improvement of diabetes" mentioned the presence of shorter-term goals than those in the responses in the theme "planning on living a long and healthy life" and represented the conviction that such goals and their achievement should lead to a better future than a future without diabetes treatment. Such goals and their achievement, that is, an accomplishment of short-term tasks, strengthen the sense of selfefficacy [16-18], and the enhancement of selfefficacy contributes to diabetes management $[11,12]$. Importantly, in the present study, the participants whose responses were included in this theme had seemingly considered diabetes management as part of their daily life, naturally using the words/phrases 'a part of my life,' 'matter of course,' and 'regulatory' in their responses; they may have set easy tasks of diabetes management and treatment in their life. Therefore, it is rational for this theme to belong to the main theme "presence of FTP with a sense of T2DM ownership," which is associated with persistent treatment engagement.

In the theme "avoiding tragic results," the avoidance of a negative outcome of T2DM was the focus instead of the pursuance of a positive outcome; in other words, participants whose responses were included in this theme may have enhanced their self-control ability by having a pessimistic outlook. One of the effective options for self-control enhancement for health is to make the future self-relatable. Duckworth et al. [19] presented a case of a physician showing young adults age-adjusted photos of themselves so they could imagine what middle age will be like and prompted them to make wise dietary choices to benefit their future self. Although such an approach to behavioral changes is a fear-based strategy, heightening health risk appraisals, the use of such a strategy alone generally has small effects on behavioral changes; thus, its use in combination with adequate coping strategies or tailored information is required [20]. The participants in the current study whose responses were included in this theme may have considered life with diabetes and its treatment in the future as selfrelatable, accompanied by an adequate strategy or information, in addition to the assumption of tragic results if treatment is discontinued.

The theme "optimistically viewing treatment as a form of self-development" was characterized by its positive feeling and future perspective regarding treatment engagement, welcoming the treatment engagement. The positive feeling toward the disease becomes a psychological resource, namely resilience, against T2DM [23]. Dubois et al. [21] examined the positive aspects of experiencing T2DM by asking questions such as "Did anything good come out of dealing with your diabetes?" and "Do you think it is likely that there is something to learn from your experience with diabetes?" using a psychological scale [22]. However, we examined the components of FTP using qualitative methods and exemplified such positive aspects of experiencing T2DM. As indicated in the response "nobody can remain healthy forever," the participants may have gained deeper insights into aging, health, and illness as a result of having T2DM and may have valued such experiences.

For the theme "improving mental health," treatment engagement may have been considered as the means of improving mental health. As a previous study indicated, various aspects of mental health, such as perceived quality of life, satisfaction, and wellbeing, tend to be reduced among T2DM patients, since diabetes leads to troubles in daily life [23]. Therefore, T2DM patients need to cope with both mental and physical health as part of self-management of the disease. Although diabetes treatment itself works for physical health, there is no doubt that improvement of one's physical health status leads to improvement of the mental health also. Health care professionals should emphasize that treatment engagement is beneficial for T2DM patients if they want to live a mentally healthy life in the future.

The theme "lack of consciousness of disease" indicated a lack of insight into the disease of the participants despite a definite diagnosis by a medical doctor. Paradoxically, improvement of insight into the disease among T2DM patients may not be achieved sufficiently by 
approaching the lack of such insight. It has been previously reported that the use of shared decision making and motivational interviewing methods increases treatment adherence based on the patient's self-determined choice in general rather than approaching the lack of insight as deliberate denial [24]. In light of this past study, the employment of such methods may be beneficial for the improvement of insight into the disease among T2DM patients and also for persistent treatment engagement.

The theme "living a dissipated life" referred to the situation in which participants had a selfdestructive life. As we illustrated, the participant who enjoyed drinking seemed to be isolated, with little hope for the future despite his understanding of the consequence of such a lifestyle; his FTP may not have included 'a sense of T2DM ownership.' The participants whose responses were included in this theme may have lacked existential and purposive meaning construction for treatment engagement; in other words, it may have been difficult for them to have an FTP for treatment because their life is filled with uncertainty. Rasmussen et al. emphasized the value of behavioral and emotional health counseling to enhance diabetes care when T2DM patients had less of a sense of purpose in life [25], and such health counseling may be effective for T2DM patients with a dissipated life.

We believe that enhancement of support to help T2DM patients have an FTP with a sense of ownership of their condition will lead to their persistent participation in their treatment. Holman and Zimbardo reported that the presence of a support network such as a spouse, romantic partner, family, and friends is associated with a high FTP [26]. Importantly, the FTP in Holman and Zimbardo's past study consisted of factors such as an ability to resist temptations for the sake of the future and a goal-oriented personality, and these factors are similar to the components of an FTP with a sense of T2DM ownership in the current study. The presence of a support network may be similarly associated with a high FTP with a sense of T2DM ownership. Health care professionals who are involved in daily health guidance, such as public health nurses, in cooperation with the local government, may be able to enhance FTP with a sense of T2DM ownership and promote persistent treatment by establishing peer support programs to create friendly relationships in the community for T2DM patients. Of note, the mean age of the subjects in the present study was 68.4 years; thus, many of the subjects may have been those who were retired. Reduced participation in social activities after retirement is often prevalent in elderly people [27]. Therefore, elderly T2DM patients, such as those in the current study, may require especially generous support to enable them to participate in the community. On the other hand, for younger T2DM patients, peer support programs in the community may reduce the risk of treatment interruption in the future because such programs may improve community ties and friendships and strengthen FTPs from a young age. Appropriate support for different age groups needs to be considered.

It is important to discuss the differences and similarities between FTP and related concepts such as treatment goals and 'glycemic happiness' to clarify the transferability and novelty of our study results. First, FTP should be differentiated from treatment goals. Living with an illness is a part of life [28], and it is thus assumed that the FTP of T2DM patients consists of not only treatment goals, but also a broad range of plans regarding how they will make sense of and deal with the disease for the rest of their lives. In addition, it was previously reported that diabetic patients are less focused on setting and achieving future goals than healthy individuals [29], suggesting that the FTP of T2DM patients may be different from those of other people. Therefore, the investigation of FTP instead of treatment goals may reveal a desired status for individuals after T2DM treatment, that is, the perceived purpose of treatment among T2DM patients.

Second, FTP may also be related to 'glycemic happiness,' which is defined as "a state of emotional and biomedical wellbeing in persons with diabetes mellitus" [30]. A scale of glycemic happiness has been developed to understand the current state of happiness in T2DM patients and their surroundings [30]. Of the items in this scale, the questions that measure mental aspects 
related to scheduling and planning taking T2DM into account, such as "Do you feel your private and social leisure activities are impaired due to diabetes?" and "Do you get angry, scared, and/or depressed when you think about living with diabetes?," are likely to be closely related to FTP. Although the present study does not examine the relationship between glycemic happiness and FTP, FTP may explain the underlying psychological mechanisms of the factors of glycemic happiness mentioned above. By exploring the relationships between FTP and psychological scales for T2DM patients, such as glycemic happiness, a scientific foundation of the tools to help T2DM patients may be improved.

The present study has two limitations. First, in the current quantitative analysis, the associations between subthemes and treatment engagement status were not examined. Subthemes consisted of more concrete components of FTP than those of main themes, which were a brief representation of such components, and thus investigation into such associations may reveal which components of FTP has a strong relationship to persistent engagement in treatment; such investigation is important for enhancing the health of T2DM patients. Second, we analyzed the data cross-sectionally and were unable to clarify the process of how the T2DM patients had established their FTP and its components shown in the current study. Behavioral and developmental scientific research on this process, namely the patient's journey, would be beneficial for diabetes management practice in terms of gaining a deeper understanding of the value and priority that T2DM patients put on their treatment.

\section{CONCLUSION}

We revealed the components of FTP of T2DM patients qualitatively and the association between main theme, as a brief representation of such components, and treatment engagement status quantitatively. The presence of FTP with a sense of T2DM ownership was associated with persistent treatment, while its absence was associated with impersistent treatment. Health care professionals should encourage T2DM patients to have an FTP and purpose in life, instead of treatment goals, if/when these individuals mention their dissipated life or lack insight into the disease.

\section{ACKNOWLEDGEMENTS}

Funding. The journal's Rapid Service Fee and analysis costs for this study were supported by Novo Nordisk Pharma Ltd.

Authorship. All named authors meet the International Committee of Medical Journal Editors (ICMJE) criteria for authorship for this article, take responsibility for the integrity of the work as a whole, and have given their approval for this version to be published.

Author Contributions. All authors contributed to the study conception, reviewing and editing of the manuscript. This study was designed by Tomoo Hidaka, Shota Endo, Takeyasu Kakamu, and Tetsuhito Fukushima. Formal analysis and preparation of original draft were performed by Tomoo Hidaka. Data collection was performed by Noriko Takahashi and Katsue Hashimoto. Data resource management and data curation were performed by Noriko Takahashi, Katsue Hashimoto, Taro Tsukahara, and Koichi Abe. Results of analysis were validated by Mariko Inoue, Yukiko Terada, Shota Endo, and Takeyasu Kakamu. Mariko Inoue and Yukiko Terada contributed to funding acquisition. This study project was supervised and administrated by Taro Tsukahara, Koichi Abe, and Tetsuhito Fukushima.

Medical Writing, Editorial, and other Assistance. We sincerely thank public health nurses of the Koriyama City Public Health Center for their data collection. We are also grateful to Yuta Ota, Taichi Shimura, Takanori Sano, and Nozomi Yamauchi of Kozo Keikaku Engineering Inc. for their tremendous support on the analysis of the database. This study was performed in the industry-government-academia collaborative research project by Novo 
Nordisk Pharma Ltd., Koriyama City, and the Department of Hygiene and Preventive Medicine at Fukushima Medical University. This study was also supported by Novo Nordisk Pharma Ltd., as a part of "Cities Changing Diabetes," a partnership program in response to the dramatic rise of diabetes in urban environments; publication and analysis costs for this study were supported by Novo Nordisk Pharma Ltd.

Disclosures. Authors Mariko Inoue and Yukiko Terada have been employed by and had a stock ownership in Novo Nordisk Pharma Ltd, and the other authors declare that they have nothing to declare.

Compliance with Ethics Guidelines. This study was approved by the Ethics Committees of Fukushima Medical University (application no. 30196). Our study was performed in accordance with the Helsinki Declaration of 1964 and its later amendments, and all participants provided written informed consent to participate in the study.

Data Availability. The datasets of qualitative study generated during and/or analyzed during the current study are not publicly available because the datasets had identifiable information of research subjects. For quantitative research, the datasets generated during and/or analyzed during the current study are available from the corresponding author on reasonable request.

Open Access. This article is licensed under a Creative Commons Attribution-NonCommercial 4.0 International License, which permits any non-commercial use, sharing, adaptation, distribution and reproduction in any medium or format, as long as you give appropriate credit to the original author(s) and the source, provide a link to the Creative Commons licence, and indicate if changes were made. The images or other third party material in this article are included in the article's Creative Commons licence, unless indicated otherwise in a credit line to the material. If material is not included in the article's Creative
Commons licence and your intended use is not permitted by statutory regulation or exceeds the permitted use, you will need to obtain permission directly from the copyright holder. To view a copy of this licence, visit http:// creativecommons.org/licenses/by-nc/4.0/.

\section{REFERENCES}

1. Zimbardo PG, Boyd JN. Putting time in psychological perspective: a valid, reliable individual-differences metric. J Pers Soc Psychol. 1999;77:1271-88.

2. Sansbury B, Dasgupta A, Guthrie L, Ward M. Time perspective and medication adherence among individuals with hypertension or diabetes mellitus. Patient Educ Couns. 2014;95:104-10. https://doi. org/10.1016/j.pec.2013.12.016.

3. Hall PA, Fong GT, Cheng AY. Time perspective and weight management behaviors in newly diagnosed Type 2 diabetes: a mediational analysis. J Behav Med. 2012;35:569-80. https://doi.org/10.1007/ s10865-011-9389-6.

4. Livneh H, Martz E. Reactions to diabetes and their relationship to time orientation. Int J Rehabil Res. 2007;30:127-36. https://doi.org/10.1097/MRR. 0b013e32813a2ed6.

5. Fong GT, Hall PA. The importance of time perspective in predicting, understanding, and reducing health risk behaviors among adolescents. In: Romer $D$, editor. Reducing adolescent risk: Toward an integrated approach. Thousand Oaks: Sage; 2003. p. 106-12.

6. Boyatzis RE. Transforming qualitative information: thematic analysis and code development. London: Sage; 1998. p. 44.

7. Lawton J, White D, Rankin D, et al. Staff experiences of closing out a clinical trial involving withdrawal of treatment: qualitative study. Trials. 2017;18:61. https://doi.org/10.1186/s13063-0171813-y.

8. Gellert P, Ziegelmann JP, Lippke S, Schwarzer R. Future time perspective and health behaviors: temporal framing of self-regulatory processes in physical exercise and dietary behaviors. Ann Behav Med. 2012;43:208-18. https://doi.org/10.1007/ s12160-011-9312-y.

9. Ida S, Kaneko R, Imataka K, Fujiwara R, Murata K. Are diabetes-related factors associated with the social roles of elderly patients with diabetes? 
J Diabetes Complicat. 2021;35: 107759. https://doi. org/10.1016/j.jdiacomp.2020.107759.

10. Dreves PA, Blackhart GC. Thinking into the future: how a future time perspective improves self-control. Pers Individ Differ. 2019;149:141-51. https:// doi.org/10.1016/j.paid.2019.05.049.

11. Yi-Frazier JP, Hilliard ME, Cochrane K, Hood KK. The impact of positive psychology on diabetes outcomes: a review. Psychology. 2012;3:1116-24. https://doi.org/10.4236/psych.2012.312A165.

12. Taylor SE, Kemeny ME, Reed GM, Bower JE, Gruenewald TL. Psychological resources, positive illusions, and health. Am Psychol. 2000;55:99-109. https://doi.org/10.1037//0003-066x.55.1.99.

13. Bito S, Matsumura S, Singer MK, Meredith LS, Fukuhara S, Wenger NS. Acculturation and end-oflife decision making: comparison of Japanese and Japanese-American focus groups. Bioethics. 2007;21:251-62.

14. Yamaguchi S, Cohen SR, Uza M. Family caregiving in Japan: the influence of cultural constructs in the care of adults with cancer. J Fam Nurs. 2016;22: 392-418.

1074840716655530 .

https://doi.org/10.1177/

15. Kawakami A, Son J. "I don't want to be a burden": Japanese immigrant acculturation and their attitudes toward non-family-based elder care. Ageing Int. 2015;40:262-76.

16. Bandura A. Self-efficacy: toward a unifying theory of behavioral change. Psychol Rev. 1977;84: 191-215. https://doi.org/10.1037/0033-295x.84.2. 191.

17. Bandura A, Schunk DH. Cultivating competence, self-efficacy, and intrinsic interest through proximal self-motivation. J Pers Soc Psychol. 1981;41: 586-98.

18. Bandura A, Cervone D. Self-evaluative and self-efficacy mechanisms governing the motivational effects of goal systems. J Pers Soc Psychol. 1983;45: 1017-28.

19. Duckworth AL, Milkman KL, Laibson D. Beyond willpower: strategies for reducing failures of selfcontrol. Psychol Sci Public Interest. 2018;19: 102-29. 1529100618821893.

20. Sheeran P, Harris PR, Epton T. Does heightening risk appraisals change people's intentions and behavior? A meta-analysis of experimental studies. Psychol Bull. 2014;140:511-43. https://doi.org/10. 1037/a0033065.
21. Dubois SK, Lehrer HM, Whyne EZ, Steinhardt MA. A resilience intervention for adults with type 2 diabetes: proof-of-concept in community health centers. Int J Behav Med. 2020;27:565-75. https:// doi.org/10.1007/s12529-020-09894-5.

22. Fredrickson BL, Tugade MM, Waugh CE, Larkin GR. What good are positive emotions in crises? A prospective study of resilience and emotions following the terrorist attacks on the United States on September 11th, 2001. J Pers Soc Psychol. 2003;84: 365-76. https://doi.org/10.1037//0022-3514.84.2. 365.

23. Saisho Y. Use of diabetes treatment satisfaction questionnaire in diabetes care: importance of patient-reported outcomes. Int J Environ Res Public Health. 2018;9(15):947. https://doi.org/10.3390/ ijerph15050947.

24. Williams AR, Olfson M, Galanter M. Assessing and improving clinical insight among patients "in denial." JAMA Psychiat. 2015;72:303-4. https://doi. org/10.1001/jamapsychiatry.2014.2684.

25. Rasmussen NH, Smith SA, Maxson JA, et al. Association of HbA1c with emotion regulation, intolerance of uncertainty, and purpose in life in type 2 diabetes mellitus. Prim Care Diabetes. 2013;7: 213-21. https://doi.org/10.1016/j.pcd.2013.04.006.

26. Holman EA, Zimbardo PG. The social language of time: the time perspective-social network connection. Basic Appl Soc Psychol. 2009;31:136-47.

27. Kobayashi E, Sugawara I, Fukaya T, Okamoto S, Liang J. Retirement and social activities in Japan: does age moderate the association? Res Aging. 2021. 01640275211005185 . https://doi.org/10.1177/

28. Sato T, Fukuda M, Hidaka T, Kido A, Nishida M, Akasaka M. The authentic culture of living well: pathways to psychological well-being. In: Valsiner $\mathrm{J}$, editor. Oxford handbook of culture and psychology. Oxford: Oxford University Press; 2012. p. 1078-91.

29. Wilczyńska A, Sikora J, Pituła B. Psychosocial context of differences between asthmatic and diabetic patients in adaptation to disease. Adv Exp Med Biol. 2016;884:61-7. https://doi.org/10.1007/5584 2015_174.

30. Kalra S, Das AK, Priya G, et al. An Expert opinion on "glycemic happiness": delineating the concept and determinant factors for persons with type 2 diabetes mellitus. Clin Pract. 2021;11:543-60. https://doi. org/10.3390/clinpract11030071. 